\title{
Vitamin E supplementation is associated with lower levels of C-reactive protein only in higher dosages and combined with other antioxidants: The Cooperative Health Research in the Region of Augsburg (KORA) F4 study
}

\author{
Sigrid Schwab ${ }^{1}$, Astrid Zierer ${ }^{1}$, Andrea Schneider ${ }^{1}$, Margit Heier ${ }^{1}$, Wolfgang Koenig ${ }^{2}$, \\ Gabi Kastenmüller ${ }^{3,4}$, Melanie Waldenberger ${ }^{1,5}$, Annette Peters ${ }^{1}$ and Barbara Thorand ${ }^{1 *}$ \\ ${ }^{1}$ Institute of Epidemiology II, Helmboltz Zentrum München - German Research Center for Environmental Health, \\ Neuberberg, Germany \\ ${ }^{2}$ Department of Internal Medicine II-Cardiology, University of Ulm Medical Center, Ulm, Germany \\ ${ }^{3}$ Institute of Bioinformatics and Systems Biology, Helmboltz Zentrum München - German Research Center for \\ Environmental Health, Neuberberg, Germany \\ ${ }^{4}$ German Center for Diabetes Research, Neuberberg, Germany \\ ${ }^{5}$ Research Unit of Molecular Epidemiology, Helmboltz Zentrum München - German Research Center for \\ Environmental Health, Neuberberg, Germany
}

(Submitted 5 November 2014 - Final revision received 29 January 2015-Accepted 2 March 2015 - First published online 21 April 2015)

\section{Abstract}

The aim of the present study was to examine the association between intake of five common antioxidative nutrients from supplements and medications (vitamin E, vitamin C, carotenoids, Se, and $\mathrm{Zn}$ ) and levels of high-sensitivity C-reactive protein (hs-CRP) in the general population. For this purpose, a total of 2924 participants of the population-based Cooperative Health Research in the Region of Augsburg (KORA) F4 study (2006-8) were investigated cross-sectionally. Intake of dietary supplements and medication during the last $7 \mathrm{~d}$ was recorded in a personal interview, when participants were asked to show product packages of ingested preparations. Linear regression models were calculated; first, the exposure to regular nutrient intake was treated with a binary response (yes/no); then regularly ingested amounts were divided into quartiles to examine dose-response relationships. Effect of single $v$. combined supplementation of antioxidants was assessed through the inclusion of interaction terms into the models. Regular intake of any of the five investigated antioxidants per se was not associated with hs-CRP levels. However, dose-response analyses revealed that participants who regularly ingested more than $78 \mathrm{mg}$ vitamin $\mathrm{E} / \mathrm{d}$, which corresponds to the upper quartile, had $22 \%$ lower hs-CRP levels (95\% CI 0.63 , 0.97) compared to those of persons who were not exposed to any vitamin E supplementation. Stratified analyses showed that this association was found only in persons who took vitamin $\mathrm{E}$ in combination with other antioxidants. The combined supplementation of vitamin $\mathrm{E}$ with other antioxidants could thus be a promising strategy for the prevention of inflammation-related diseases in the general population, if further studies could confirm that the proposed association is causal.

\section{Key words: Vitamin E supplementation: Antioxidative supplements: High-sensitivity C-reactive protein:} Population-based studies

Subclinical inflammation processes are closely related to the development of common chronic diseases. Healthy subjects with higher concentrations of the inflammatory marker C-reactive protein (CRP) have a higher risk of developing CVD and type 2 diabetes within the next years ${ }^{(1,2)}$. Thus, dietary supplements with antioxidative or immune modulating properties might be an effective strategy for the prevention of inflammation-related diseases at the population level.
However, results from epidemiological studies on antioxidant intake and CRP levels present conflicting scenarios ${ }^{(3,4)}$. Low intake of vitamin $\mathrm{C}$ and carotenoids was associated with elevated CRP levels in one study ${ }^{(4)}$, whereas their association was found to be non-significant in another study ${ }^{(3)}$. Furthermore, another study found a significant inverse association of vitamin $\mathrm{E}$ and CRP only in women ${ }^{(3)}$, while yet another study reported a such significant association in both men

Abbreviations: CRP, C-reactive protein; hs-CRP, high-sensitivity C-reactive protein; KORA, Cooperative Health Research in the Region of Augsburg. 
and women ${ }^{(4)}$. Therefore, it is not clear if there are sex specific effects. As intervention studies are usually conducted on diseased or high-risk samples ${ }^{(5-9)}$, conclusions cannot be drawn from them for the general healthy population. Moreover, it is possible that effects of intakes of single nutrients differ from those of combined intakes, because nutrients might interact with each other. Besides, there might be dose-effect relationships, which need close investigation ${ }^{(3)}$. Intervention studies which are most reliable to detect effects of nutrient supplementation should begin with sufficient evidence from observational studies on specific target populations, most effective nutrient combinations, and possible dose-response effects. The aim of the present study was, therefore, to investigate the association between intakes of common antioxidative vitamins and minerals from supplements and medications (vitamin E, vitamin C, carotenoids, Se, and $\mathrm{Zn})^{(10)}$ with levels of high-sensitivity C-reactive protein (hs-CRP) in the general population. In this respect, dose-response relationships, effects of single $v$. multiple use of antioxidants, and potential sex-specific effects were examined.

\section{Methods}

Data are based on the German Cooperative Health Research in the Region of Augsburg (KORA) F4 study (2006-8), a follow-up examination of the population-based KORA S4 survey $(1999-2001)^{(11)}$. Exclusion criteria for the present investigation were hs-CRP levels $>10 \mathrm{mg} / \mathrm{l}^{(1)}$, pregnancy and missing values in any exposure, outcome or confounder ( $n$ 155). This study was conducted according to the guidelines laid down in the Declaration of Helsinki and all procedures involving human subjects were approved by the ethics committee of the Bavarian Chamber of Physicians (Munich, Germany). Written informed consent was obtained from all participants.

For assessment of the outcome hs-CRP, fasting blood samples were collected in the morning, kept at $4^{\circ} \mathrm{C}$ until centrifugation and stored at $-80^{\circ} \mathrm{C}$ until laboratory measurements. Hs-CRP was measured of EDTA plasma samples with a high-sensitivity latex-enhanced nephelometric assay on a BN II analyzer (Siemens); intra-assay and interassay $\mathrm{CV}$ were $<5 \%$ and $<10 \%$, respectively.

For exposure assessment, intake of dietary supplements during the last $7 \mathrm{~d}$ was recorded together with medication used through computer-based software ${ }^{(12)}$ in a personal interview, when participants were asked to show product packages of ingested preparations ${ }^{(13)}$. Vitamins and minerals not only from supplements, but also from medications were taken into consideration for the investigation of the etiological association between nutrients and hs-CRP levels, as the same ingredients (e.g. $\alpha$-tocopherol) can be marketed either as supplements or as medications in Germany. Relative serum $\alpha$-tocopherol levels were measured in a subgroup of 1685 subjects (CV: 19.3\%), as part of a non-targeted metabolomics experiment using GC coupled with MS (GC-MS). Serum samples that were collected after overnight fasting during the KORA F4 examinations were analysed at Metabolon,
Inc., a commercial supplier of metabolomics measurements $^{(14)}$. The measurement followed established protocols as described earlier ${ }^{(15,16)}$. Raw quantification values (ion counts) were normalized to the median of the samples measured at the same run day to account for inter-day variation of the instrument. Normalized values were log-transformed and values above or below four standard deviations from the mean were excluded from further analysis.

Confounders were selected on the basis of practices followed in literature. Fully adjusted models included the following covariables: age (continuous), sex, education (low/high), BMI (continuous), BMI ${ }^{2}$ (continuous), physical activity (active/inactive), smoking (current/former/never), alcohol consumption (none/moderate/high), cholesterol:HDL ratio (continuous), actual hypertension (yes/no), CVD (yes/no), diabetes (yes/no), non-steroidal anti-inflammatory drug use (yes/no), and statin use (yes/no). In sensitivity analyses, regression models were additionally adjusted for the use of other dietary supplements, and for the use of hormone therapy and oral contraceptives in women.

\section{Data collection and description of covariables}

Covariables were collected through a personal interview or measured during an examination at the study centre. For age, the actual age at examination was recdorded. Information about years of education was collected in the baseline S4 study (1999-2001) ${ }^{(11)}$ and summarized as years at school plus professional education. The variable was dichotomized into low ( $8-10$ years) and high (11-17 years) education. For calculating the BMI, participants' weight and height were measured. Categories as per the WHO standard were applied to the classification in Table $1^{(17)}$. Physical activity included frequency and duration of activity in summer and in winter and was divided into active and inactive ${ }^{(18)}$. Smoking was defined as smoking cigarettes and categorized as current (further subdivided into 'regularly' and 'irregularly'), former and never. Irregular smoking was defined as usually smoking less than 1 cigarette/d. Alcohol intake was assessed as daily average intake based on the consumption of last weekend and the last weekday before the examination, following the validated recall method of Döring et $a l^{(19)}$. Moderate consumption was defined as more than zero and less than $40 \mathrm{~g}$ alcohol $/ \mathrm{d}$ in men, and more than zero and less than $20 \mathrm{~g} / \mathrm{d}$ in women; and high consumption was defined as $40 \mathrm{~g} / \mathrm{d}$ or more in men, and $20 \mathrm{~g} / \mathrm{d}$ or more in women ${ }^{(20)}$. For serum cholesterol measurement, blood was drawn from sedentary participants in the morning after an overnight fast of at least $8 \mathrm{~h}$. Total cholesterol was measured using the Boehringer CHOD-PAP method (inter-assay CV: $\leq 2.1 \%$; Roche Diagnostics). HDL-cholesterol was measured using the phosphotungstic acid method (inter-assay CV: $\leq 3.5 \%$; Boehringer Mannheim). Cut-off points for total:HDLcholesterol ratio used for description in Table 1 were defined according to the American Heart Association ${ }^{(21)}$. A participant was classified as hypertensive if the mean of the second and the third blood pressure measurements met the criteria of the WHO for hypertension, i.e. a systolic pressure 
Table 1. C-reactive protein (CRP) levels by categories of covariables in KORA F4 (Cooperative Health Research in the Region of Augsburg) (Geometric mean values and antilog standard deviations, $n$ 2924)

\begin{tabular}{|c|c|c|c|c|c|c|}
\hline \multirow[b]{3}{*}{ Characteristic } & \multirow[b]{3}{*}{$n$} & \multicolumn{4}{|c|}{ hs-CRP (mg/l) } & \multirow[b]{3}{*}{$P$ for mean difference } \\
\hline & & \multicolumn{2}{|c|}{ Unadjusted } & \multicolumn{2}{|c|}{ Adjusted $†$} & \\
\hline & & Geometric mean & Antilog SD & Geometric mean & Antilog SD & \\
\hline Age (years) & & & & & & $<0.0001$ \\
\hline $31-43$ & 659 & 0.84 & 2.89 & 0.84 & $2 \cdot 67$ & \\
\hline$>43-52$ & 569 & 0.93 & 2.75 & 0.92 & 2.68 & \\
\hline$>52-60$ & 557 & 1.19 & 2.63 & $1 \cdot 18^{\star \star \star}$ & $2 \cdot 67$ & \\
\hline$>60-70$ & 636 & 1.43 & 2.56 & $1.43^{\star \star \star}$ & $2 \cdot 67$ & \\
\hline$>70-82$ & 503 & 1.46 & 2.50 & $1.46^{\star \star \star}$ & $2 \cdot 67$ & \\
\hline Sex & & & & & & 0.0082 \\
\hline Female & 1511 & $1 \cdot 18$ & $2 \cdot 82$ & 1.18 & $2 \cdot 67$ & \\
\hline Male & 1413 & 1.08 & 2.66 & 1.08 & $2 \cdot 67$ & \\
\hline Education (years) & & & & & & $<0.0001$ \\
\hline $8-10$ & 1299 & 1.37 & 2.62 & 1.28 & 2.72 & \\
\hline $11-17$ & 1625 & 0.97 & 2.77 & 1.02 & $2 \cdot 70$ & \\
\hline BMI $\left(\mathrm{kg} / \mathrm{m}^{2}\right) \S$ & & & & & & $<0.0001$ \\
\hline$<25$ & 937 & 0.69 & 2.69 & 0.71 & 2.57 & \\
\hline $25-<30$ & 1230 & $1 \cdot 16$ & 2.49 & $1 \cdot 16^{\star \star *}$ & 2.51 & \\
\hline$\geq 30$ & 757 & 1.99 & 2.39 & $1.91^{* \star *}$ & 2.52 & \\
\hline Physical activity & & & & & & $<0.0001$ \\
\hline Active & 1604 & 0.99 & $2 \cdot 72$ & 1.00 & 2.65 & \\
\hline Inactive & 1320 & 1.33 & $2 \cdot 71$ & 1.31 & 2.65 & \\
\hline Smoking & & & & & & $<0.0001$ \\
\hline Current $\|$ & 528 & $1 \cdot 17$ & 2.79 & 1.33 & 2.72 & \\
\hline Former & 1091 & $1 \cdot 15$ & $2 \cdot 74$ & $1 \cdot 13^{\star \star}$ & $2 \cdot 68$ & \\
\hline Never & 1305 & 1.09 & $2 \cdot 72$ & $1.05^{\star \star \star}$ & $2 \cdot 71$ & \\
\hline Alcohol consumptionq & & & & & & $<0.0001$ \\
\hline None & 882 & 1.31 & 2.77 & 1.28 & $2 \cdot 71$ & \\
\hline Moderate & 1532 & 1.06 & 2.69 & $1.08^{\star * *}$ & $2 \cdot 67$ & \\
\hline High & 510 & 1.05 & $2 \cdot 79$ & $1.05^{\star \star *}$ & $2 \cdot 66$ & \\
\hline Cholesterol:HDL ratio & & & & & & $<0.0001$ \\
\hline$<3.5$ & 1012 & 0.86 & 2.76 & 0.85 & 2.69 & \\
\hline$\geq 3.5-<5.0$ & 1330 & 1.22 & 2.67 & $1 \cdot 20^{* \star *}$ & $2 \cdot 61$ & \\
\hline$\geq 5 \cdot 0$ & 582 & 1.55 & 2.55 & $1 \cdot 60^{\star * *}$ & 2.64 & \\
\hline Hypertension†† & & & & & & $<0.0001$ \\
\hline No & 1826 & 0.95 & $2 \cdot 74$ & 1.00 & 2.79 & \\
\hline Yes & 1098 & 1.50 & 2.57 & 1.37 & $2 \cdot 86$ & \\
\hline 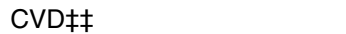 & & & & & & 0.0003 \\
\hline No & 2628 & 1.09 & 2.73 & $1 \cdot 10$ & 2.67 & \\
\hline Yes & 296 & 1.60 & $2 \cdot 66$ & 1.38 & $2 \cdot 73$ & \\
\hline Diabetes & & & & & & 0.0053 \\
\hline No & 2725 & $1 \cdot 10$ & 2.75 & $1 \cdot 11$ & $2 \cdot 67$ & \\
\hline Yes & 199 & 1.64 & 2.53 & 1.37 & 2.73 & \\
\hline NSAID§§ & & & & & & 0.0108 \\
\hline No & 2834 & $1 \cdot 12$ & 2.75 & 1.12 & $2 \cdot 67$ & \\
\hline Yes & 90 & 1.61 & 2.52 & 1.46 & 2.67 & \\
\hline Statins & & & & & & 0.7008 \\
\hline No & 2575 & $1 \cdot 10$ & 2.77 & 1.12 & 2.69 & \\
\hline Yes & 349 & 1.38 & 2.48 & 1.15 & 2.79 & \\
\hline Hormone therapy|||| & & & & & & 0.7552 \\
\hline No & 1384 & $1 \cdot 17$ & $2 \cdot 84$ & 1.18 & 2.74 & \\
\hline Yes & 127 & 1.24 & $2 \cdot 60$ & 1.15 & 2.75 & \\
\hline Use of oral contraceptives ||| & & & & & & $<0.0001$ \\
\hline No & 1415 & 1.15 & $2 \cdot 80$ & 1.12 & $2 \cdot 71$ & \\
\hline Yes & 96 & 1.65 & 3.03 & 2.35 & $2 \cdot 83$ & \\
\hline
\end{tabular}

hs-CRP, high sensitivity C-reactive protein; NSAID, non-steroidal anti-inflammatory drugs.

Mean value was significantly different compared with the first category: ${ }^{\star \star} P<0.01,{ }^{\star \star \star} P<0.001$.

† Adjusted for age (continuous) and sex; age was only adjusted for sex and sex was only adjusted for age.

$\ddagger P$ for age- and sex-adjusted mean difference (ANCOVA).

$\S \mathrm{BMI}<18.5 \mathrm{~kg} / \mathrm{m}^{2}(n 10)$ and $18.5 \leq \mathrm{BMI}<25(n$ 927) were combined.

$\|$ Smoking regularly $(n 450)$ and irregularly $(n 78)$ were combined.

If Moderate: men $>0$ to $<40 \mathrm{~g} / \mathrm{d}$; women $>0$ to $<20 \mathrm{~g} / \mathrm{d}$; high: men $\geq 40 \mathrm{~g} / \mathrm{d}$; women $\geq 20 \mathrm{~g} / \mathrm{d}$.

†† Actual hypertension ( $\geq 140 / 90 \mathrm{mmHg}$ ) or intake of antihypertensive medication and awareness of being hypertensive.

$\ddagger \ddagger$ History of myocardial infarction, stroke or angina pectoris.

$\S \S$ Without acetylsalicylic acid in dosages of 100 or $300 \mathrm{mg}$.

||| In women only. 
$\geq 140 \mathrm{mmHg}$ and/or diastolic $\geq 90 \mathrm{mmHg}^{(22)}$, or if the participant was taking antihypertensive medication and was aware of being hypertensive. CVD was defined as a participant's having a history of myocardial infarction or stroke (treated as an inpatient, self-reported), or a history of angina pectoris (self-reported). Diabetes mellitus was defined according to self-report or current use of antidiabetic drugs. Medication intake during the last $7 \mathrm{~d}$ was collected from product packages showed by participants, and recorded through a database supported computer software ${ }^{(12)}$. For the definition of nonsteroidal anti-inflammatory drugs, regular use was considered, and acetylsalicylic acid use in dosages of 100-300 mg was not included. Hormone therapy was defined as use of systemic estrogens with or without gestagen intake. The adjustment variable dietary supplement intake, that was used for sensitivity analysis, was built including supplementation of any of the following nutrients which have been found to be associated with CRP levels: vitamin $\mathrm{A}, \mathrm{D}, \mathrm{B}_{1}, \mathrm{~B}_{2}, \mathrm{~B}_{6}, \mathrm{~B}_{12}$, folic acid, pantothenic acid, niacin, biotin, Mg, Fe, DHA, EPA, $\alpha$-linolenic acid, glucosamine and chondroitin ${ }^{(3,23-34)}$.

\section{Statistical analysis}

Age- and sex-adjusted mean levels of hs-CRP by categories of covariables and exposure variables were compared using ANCOVA. If the $P$-value for the group was $<0.05$, post hoc analyses were performed with the first category as reference group, to clarify where the differences are. For statistical analyses, hs-CRP was log-transformed to approximate a normal distribution, and back-transformed for presentation of results. These are displayed as ratio (95\% CI) of geometric mean hs-CRP levels among nutrient users $v$. non-users. The association of vitamin E, vitamin $\mathrm{C}$, carotenoids, Se and $\mathrm{Zn}$ intake with hs-CRP was investigated cross-sectionally using linear regression models; initially total regular nutrient intake was treated binary (yes/no), then regularly ingested amounts were divided into quartiles to investigate dose-response effects. The reference group comprised persons with a zero intake of the nutrients of interest from supplements or medications. Assumptions of linear regression models were checked and fulfilled. Effect modification was tested for sex, and intake of at least one of the other four antioxidants, respectively. Through the latter we examined the effect of single $v$. combined supplementation of antioxidants, i.e., if the association of each nutrient with hs-CRP depends on the intake of at least one of the other four antioxidants, or if supplementation of each nutrient in isolation (without other antioxidants) is associated with hs-CRP. An independent effect of each antioxidant was assessed via adjustment for use of at least one of the other four antioxidants, respectively. We used a spline, i.e. a piecewise polynomial function, to examine a non-linear relationship between regularly ingested vitamin E amounts and hs-CRP levels. The Spearman correlation coefficient was calculated to assess the correlation between average daily intake amounts of vitamin $\mathrm{E}$ from supplements, and serum levels of $\alpha$-tocopherol, in regular vitamin E supplement users. Linear regression analyses were conducted for regular vitamin E supplement users dividing the exposure serum $\alpha$-tocopherol levels into quartiles with the first quartile as reference group; and effect modification through intake of at least one of the other four antioxidants (vitamin $\mathrm{C}$, carotenoids, Se, and $\mathrm{Zn}$ ) was investigated by inclusion of the respective interaction terms in the models. The quadratic term of $\mathrm{BMI}\left(\mathrm{BMI}^{2}\right)$ was used in the analyses in addition to BMI, because of a non-linear relationship of BMI with hs-CRP. Statistical analyses were performed using Statistical Analysis Systems version 9.3 (SAS Institute, Inc.).

\section{Results}

The final study population comprised 2924 participants (1413 men, 1511 women) with a mean age of 56 years, ranging from 31 to 82 years. Frequency of regular antioxidant intake was $9 \cdot 1 \%$ for vitamin E, $9 \cdot 2 \%$ for vitamin C, $4.0 \%$ for carotenoids, $5.0 \%$ for Se, and $6.9 \%$ for $\mathrm{Zn}$. Frequencies of sex-specific intakes and intakes as needed are presented in Table 2. The geometric mean hs-CRP concentration in the study population was 1.13 (antilog SD 2.74) mg/l. Unadjusted and adjusted geometric means by categories of covariables are provided in Table 1, and by categories of exposure variables in Table 3.

Regular intake of any of the five investigated antioxidative nutrients per se was not associated with hs-CRP (Table 4). However, dose-effect analyses revealed that regular intake of more than $78 \mathrm{mg}$ vitamin $\mathrm{E}$, which corresponds to the top quartile, was significantly associated with lower hs-CRP levels. In fully adjusted analyses hs-CRP levels of persons who ingested more than $78 \mathrm{mg}$ vitamin E/d were $22 \%$ lower compared to those of participants who did not ingest any vitamin E from supplements or medications (Table 4). This association persisted after additional adjustment for the use of at least one of the other four antioxidants (Table 4) and

Table 2. Use of antioxidative supplements in KORA F4 (Cooperative Health Research in the Region of Augsburg)

(Number of subjects and percentages, $n$ 2924)

\begin{tabular}{|c|c|c|c|c|c|c|}
\hline \multirow[b]{2}{*}{ Nutrient } & \multicolumn{2}{|c|}{ Men } & \multicolumn{2}{|c|}{ Women } & \multicolumn{2}{|c|}{ Total } \\
\hline & $n$ & $\%$ & $n$ & $\%$ & $n$ & $\%$ \\
\hline \multicolumn{7}{|l|}{ Vitamin E } \\
\hline No intake & 1281 & $90 \cdot 7$ & 1325 & $87 \cdot 7$ & 2606 & $89 \cdot 1$ \\
\hline Regular intake & 109 & $7 \cdot 7$ & 156 & $10 \cdot 3$ & 265 & $9 \cdot 1$ \\
\hline Intake as needed & 23 & 1.6 & 30 & $2 \cdot 0$ & 53 & 1.8 \\
\hline \multicolumn{7}{|l|}{ Vitamin C } \\
\hline No intake & 1241 & $87 \cdot 8$ & 1285 & $85 \cdot 0$ & 2526 & 86.4 \\
\hline Regular intake & 114 & $8 \cdot 1$ & 156 & $10 \cdot 3$ & 270 & $9 \cdot 2$ \\
\hline Intake as needed & 58 & $4 \cdot 1$ & 70 & 4.6 & 128 & 4.4 \\
\hline \multicolumn{7}{|l|}{ Carotenoids } \\
\hline No intake & 1360 & $96 \cdot 3$ & 1433 & $94 \cdot 8$ & 2793 & 95.5 \\
\hline Regular intake & 48 & 3.4 & 68 & 4.5 & 116 & 4.0 \\
\hline Intake as needed & 5 & 0.4 & 10 & 0.7 & 15 & 0.5 \\
\hline \multicolumn{7}{|l|}{$\mathrm{Se}$} \\
\hline No intake & 1346 & $95 \cdot 3$ & 1417 & 93.8 & 2763 & 94.5 \\
\hline Regular intake & 58 & $4 \cdot 1$ & 88 & 5.8 & 146 & 5.0 \\
\hline Intake as needed & 9 & 0.6 & 6 & 0.4 & 15 & 0.5 \\
\hline \multicolumn{7}{|l|}{$\mathrm{Zn}$} \\
\hline No intake & 1321 & 93.5 & 1363 & $90 \cdot 2$ & 2684 & 91.8 \\
\hline Regular intake & 76 & 5.4 & 127 & 8.4 & 203 & 6.9 \\
\hline Intake as needed & 16 & 1.1 & 21 & 1.4 & 37 & 1.3 \\
\hline
\end{tabular}


Table 3. C-reactive protein (CRP) levels by categories of exposure variables in KORA F4 (Cooperative Health Research in the Region of Augsburg) (Geometric mean values and antilog standard deviations, $n$ 2924)

\begin{tabular}{|c|c|c|c|c|c|c|c|c|}
\hline \multirow{3}{*}{$\begin{array}{l}\text { Antioxidative } \\
\text { nutrient }\end{array}$} & \multirow[b]{3}{*}{ Intake } & \multirow{3}{*}{$\begin{array}{c}\text { Quartile } \\
\text { boundaries }\end{array}$} & \multirow[b]{3}{*}{$n$} & \multicolumn{4}{|c|}{ hs-CRP (mg/l) } & \multirow{3}{*}{$\begin{array}{l}P \text { for mear } \\
\text { difference }\end{array}$} \\
\hline & & & & \multicolumn{2}{|c|}{ Unadjusted } & \multicolumn{2}{|c|}{ Adjusted* } & \\
\hline & & & & Geometric mean & Antilog SD & Geometric mean & Antilog SD & \\
\hline \multirow{6}{*}{ Vitamin E } & & $\mathrm{mg} / \mathrm{d}$ & & & & & & 0.0646 \\
\hline & No intake & - & 2606 & $1 \cdot 13$ & $2 \cdot 75$ & $1 \cdot 14$ & $2 \cdot 67$ & \\
\hline & Quartile 1 & $0-\leq 10$ & 81 & $1 \cdot 10$ & $2 \cdot 70$ & 1.01 & $2 \cdot 67$ & \\
\hline & Quartile 2 & $10-\leq 20$ & 55 & $1 \cdot 16$ & $2 \cdot 65$ & 1.07 & $2 \cdot 67$ & \\
\hline & Quartile 3 & $20-\leq 78$ & 63 & 1.40 & 2.56 & 1.20 & $2 \cdot 68$ & \\
\hline & Quartile 4 & $>78$ & 66 & 0.98 & $2 \cdot 59$ & $0 \cdot 81$ & $2 \cdot 69$ & \\
\hline \multirow[t]{6}{*}{ Vitamin C } & & $\mathrm{mg} / \mathrm{d}$ & & & & & & 0.1215 \\
\hline & No intake & - & 2526 & $1 \cdot 15$ & $2 \cdot 74$ & $1 \cdot 15$ & $2 \cdot 67$ & \\
\hline & Quartile 1 & $0-\leq 60$ & 84 & 1.08 & $2 \cdot 76$ & 0.98 & $2 \cdot 67$ & \\
\hline & Quartile 2 & $60-\leq 120$ & 62 & 1.40 & $2 \cdot 46$ & 1.26 & $2 \cdot 67$ & \\
\hline & Quartile 3 & $120-\leq 275$ & 57 & 1.01 & $2 \cdot 54$ & 0.93 & $2 \cdot 67$ & \\
\hline & Quartile 4 & $>275$ & 67 & 0.99 & $2 \cdot 57$ & 0.99 & $2 \cdot 67$ & \\
\hline \multirow[t]{6}{*}{ Carotenoids } & & $\mathrm{mg} / \mathrm{d}$ & & & & & & 0.7030 \\
\hline & No intake & - & 2793 & $1 \cdot 13$ & 2.75 & $1 \cdot 13$ & $2 \cdot 67$ & \\
\hline & Quartile 1 & $0-\leq 1$ & 29 & $1 \cdot 29$ & $2 \cdot 41$ & $1 \cdot 20$ & $2 \cdot 67$ & \\
\hline & Quartile 2 & $1-\leq 3$ & 29 & $1 \cdot 15$ & $2 \cdot 68$ & 1.05 & $2 \cdot 67$ & \\
\hline & Quartile 3 & $3-\leq 8$ & 31 & 1.08 & $2 \cdot 59$ & 0.95 & $2 \cdot 67$ & \\
\hline & Quartile 4 & $>8$ & 27 & 1.41 & $2 \cdot 41$ & $1 \cdot 16$ & $2 \cdot 68$ & \\
\hline \multirow[t]{6}{*}{$\mathrm{Se}$} & & $\mu \mathrm{g} / \mathrm{d}$ & & & & & & $0 \cdot 1665$ \\
\hline & No intake & - & 2763 & $1 \cdot 13$ & $2 \cdot 75$ & $1 \cdot 14$ & $2 \cdot 67$ & \\
\hline & Quartile 1 & $0-\leq 25$ & 69 & 1.25 & 2.53 & $1 \cdot 12$ & $2 \cdot 67$ & \\
\hline & Quartile 2 & $25-\leq 30$ & 17 & $1 \cdot 13$ & $2 \cdot 89$ & 1.07 & $2 \cdot 67$ & \\
\hline & Quartile 3 & $30-\leq 60$ & 27 & 0.85 & $2 \cdot 32$ & 0.73 & $2 \cdot 67$ & \\
\hline & Quartile 4 & $>60$ & 33 & 0.96 & $2 \cdot 84$ & 0.89 & $2 \cdot 67$ & \\
\hline \multirow[t]{4}{*}{ Zn‡ } & & & & & & & & 0.2652 \\
\hline & No intake & - & 2684 & $1 \cdot 14$ & 2.74 & $1 \cdot 14$ & $2 \cdot 67$ & \\
\hline & Regular intake & - & 203 & 1.09 & $2 \cdot 69$ & 1.02 & $2 \cdot 68$ & \\
\hline & Intake as needed & - & 37 & 0.96 & $3 \cdot 11$ & 1.06 & $2 \cdot 67$ & \\
\hline
\end{tabular}

hs-CRP, high sensitivity C-reactive protein.

* Adjusted for age (continuous) and sex.

$\dagger P$ for age- and sex-adjusted mean difference (ANCOVA).

¥Division into quartiles was not possible due to distribution, because $40 \%$ of persons with regular intakes ingested $5 \mathrm{mg} Z \mathrm{Z} / \mathrm{d}$.

other nutrient supplements (ratio 0.79 (95\% CI 0.63 , 0.99)). A spline $\left(P=0.25, \chi^{2}\right.$ test $)$ did not improve significantly the description of the association between regularly ingested vitamin E amounts and hs-CRP compared to the linear model.

The interaction term of regular vitamin $\mathrm{E}$ use in the top quartile and use of any of the other four antioxidants was significant with a $P$-value of 0.028 . Stratification according to single vitamin E supplementation (without the use of any of the other four antioxidants) and supplementation of vitamin $\mathrm{E}$ in combination with at least one of the other antioxidants showed that associations were confined to those, who ingested vitamin $\mathrm{E}$ in combination with at least one other antioxidant (ratio 0.66 (95\% CI 0.48, 0.90)), but the same could not be seen in those with supplementation of vitamin $\mathrm{E}$ alone (ratio 1.09 (95\% CI 0.77, 1.56)) (see Fig. 1).

Participants in the highest vitamin E quartile ( $n$ 66) were $54.6 \%$ female and ingested mean vitamin $\mathrm{E}$ amounts of 256 (sD 141$) \mathrm{mg} / \mathrm{d}$. In persons who ingested vitamin $\mathrm{E}$ in combination with other antioxidants ( $n$ 42), the most frequent combination was use of all five antioxidants ( $n$ 14), followed by vitamin $\mathrm{E}$ with vitamin $\mathrm{C}(n 7)$. Only five participants of the forty-two did not supplement vitamin E together with vitamin C.

Effect modification by sex using quartiles of vitamin $\mathrm{E}$ as exposure was not seen $(P=0 \cdot 80)$. However, stratified analyses revealed a stronger association in women, whereas the association was weaker and non-significant in men (ratios for highest vitamin E quartiles: 0.72 (95\% CI 0.52, 0.98) and 0.88 (95\% CI $0.63,1.23$ ), respectively). Further adjustment for hormone therapy and use of oral contraceptives in women did not alter results substantially (data not shown).

As a sensitivity analysis, the relationship between serum levels of $\alpha$-tocopherol and hs-CRP concentrations in persons who regularly ingested vitamin E supplements was investigated ( $n$ 165) (see online Supplementary Table S1). The correlation coefficient between average intake amounts of vitamin $\mathrm{E}$ and serum levels of $\alpha$-tocopherol was 0.53 $(P<0 \cdot 001)$. Ratios for the association of serum $\alpha$-tocopherol concentrations with hs-CRP from linear regression analyses decreased non-significantly for $\alpha$-tocopherol quartile numbers two, three and four $v$. one as follows respectively: $1.03(95 \%$ CI $0.70,1.52), P=0.88 ; 0.83$ (95\% CI $0.56,1.23), P=0.36 ; 0.79$ (95\% CI $0.53,1.17$ ),$P=0.23$ (see online Supplementary Table S1). The $P$-value for the interaction with intake of at least one of the other four antioxidants was 0.0260. In persons who ingested other antioxidants as well, higher $\alpha$-tocopherol levels compared to lower values showed a tendency to be associated with lower hs-CRP levels (ratios for quartiles three and four $v$. one, respectively: 0.85 (95\% CI 0.56, 1.29), 
Table 4. Dose-response relationship between regular nutrient intake with high sensitivity C-reactive protein (hs-CRP) levels (linear regression) (Ratios and $95 \%$ confidence intervals of geometric means)

\begin{tabular}{|c|c|c|c|c|c|c|c|c|c|c|c|}
\hline \multirow[b]{3}{*}{ Antioxidant nutrient } & \multirow[b]{3}{*}{ Model } & \multicolumn{10}{|c|}{ hs-CRP levels* } \\
\hline & & \multicolumn{2}{|c|}{ Regular intake $\dagger$} & \multicolumn{2}{|c|}{ Quartile 1} & \multicolumn{2}{|c|}{ Quartile 2} & \multicolumn{2}{|c|}{ Quartile 3} & \multicolumn{2}{|c|}{ Quartile 4} \\
\hline & & Ratio & $95 \% \mathrm{Cl}$ & Ratio & $95 \% \mathrm{Cl}$ & Ratio & $95 \% \mathrm{Cl}$ & Ratio & $95 \% \mathrm{Cl}$ & Ratio & $95 \% \mathrm{Cl}$ \\
\hline \multirow[t]{5}{*}{ Vitamin E } & & & & \multicolumn{2}{|c|}{$0<-\leq 10 \mathrm{mg} / \mathrm{d}$} & \multirow{2}{*}{\multicolumn{2}{|c|}{$\begin{array}{c}10<-\underset{55}{\leq} 20 \mathrm{mg} / \mathrm{d} \\
\end{array}$}} & \multirow{2}{*}{\multicolumn{2}{|c|}{$\begin{array}{c}20<-\underset{63}{\leq} 78 \mathrm{mg} / \mathrm{d} \\
\text { d }\end{array}$}} & \multirow{2}{*}{\multicolumn{2}{|c|}{$\begin{array}{c}>78 \mathrm{mg} / \mathrm{d} \\
66\end{array}$}} \\
\hline & $\begin{array}{l}n \\
\text { Unadiusted }\end{array}$ & \multicolumn{2}{|c|}{265} & \multicolumn{2}{|c|}{81} & & & & & & \\
\hline & $\begin{array}{l}\text { Age- and sex-adjusted } \\
\text { Agted }\end{array}$ & 0.88 & $0.78,1.00$ & 0.88 & $0 \cdot 71,1 \cdot 10$ & 0.93 & $0.72,1.21$ & 1.05 & $0.82,1.34$ & $\begin{array}{l}0.87 \\
0.71\end{array}$ & $0.56,0.90$ \\
\hline & Fully adjusted $\ddagger$ & 0.96 & $0.86,1.07$ & 0.94 & $0.77,1.14$ & 0.99 & $0.79,1.26$ & 1.19 & $0.95,1.48$ & 0.78 & $0.63,0.97$ \\
\hline & Fully adjusted $\ddagger+$ other antioxidants & 0.96 & $0.83,1 \cdot 10$ & 0.95 & $0.77,1.17$ & 1.00 & $0.78,1.29$ & $1 \cdot 20$ & $0.95,1.53$ & 0.79 & $0.63,0.99$ \\
\hline \multirow[t]{6}{*}{ Vitamin C } & & & & \multicolumn{2}{|c|}{$0<-\leq 60 \mathrm{mg} / \mathrm{d}$} & \multirow{2}{*}{\multicolumn{2}{|c|}{$60<-\leq 120 \mathrm{mg} / \mathrm{d}$}} & \multirow{2}{*}{\multicolumn{2}{|c|}{$120<-\leq 275 \mathrm{mg} / \mathrm{d}$}} & \multicolumn{2}{|c|}{$>275 \mathrm{mg} / \mathrm{d}$} \\
\hline & $n$ & \multicolumn{2}{|c|}{270} & \multicolumn{2}{|c|}{84} & & & & & & 37 \\
\hline & Unadjusted & 0.96 & $0.85,1.09$ & 0.94 & $0.75,1.17$ & 1.22 & $0.95,1.58$ & 0.88 & $0.68,1.15$ & 0.86 & $0.68,1 \cdot 10$ \\
\hline & Age- and sex-adjusted & 0.90 & $0.79,1.02$ & 0.86 & $0.69,1.06$ & $1 \cdot 10$ & $0.86,1.41$ & 0.81 & $0.63,1.05$ & 0.87 & $0.68,1 \cdot 10$ \\
\hline & Fully adjusted & 1.02 & $0.91,1.14$ & 0.98 & $0.81,1.18$ & $1 \cdot 17$ & $0.94,1.46$ & 0.96 & $0.76,1.21$ & 1.00 & $0.81,1.23$ \\
\hline & Fully adjusted $\ddagger+$ other antioxidants & 1.08 & $0.93,1.25$ & 1.03 & $0.83,1.28$ & 1.24 & $0.97,1.59$ & 1.01 & $0.79,1.31$ & 1.05 & $0.83,1.33$ \\
\hline Carotenoids & & & & $0<$ & $\leq 1 \mathrm{mg} / \mathrm{d}$ & $1<$ & $\leq 3 \mathrm{mg} / \mathrm{d}$ & $3<$ & $\leq 8 \mathrm{mg} / \mathrm{d}$ & & $\mathrm{mg} / \mathrm{d}$ \\
\hline & $n$ & & 16 & & 29 & & 29 & & 31 & & 27 \\
\hline & Unadjusted & 1.08 & $0.90,1.30$ & $1 \cdot 14$ & $0.79,1.65$ & 1.01 & $0.70,1.47$ & 0.96 & $0.67,1.37$ & $1 \cdot 25$ & $0.85,1.83$ \\
\hline & Age- and sex-adjusted & 0.95 & $0.79,1 \cdot 15$ & 1.06 & $0.74,1.52$ & 0.93 & $0.65,1.33$ & 0.84 & $0.59,1 \cdot 18$ & 1.03 & $0.71,1.49$ \\
\hline & Fully adjusted $\ddagger$ & 1.09 & $0.93,1.29$ & $1 \cdot 21$ & $0.88,1.67$ & $1 \cdot 11$ & $0.80,1.53$ & 1.04 & $0.76,1.42$ & 1.02 & $0.73,1.42$ \\
\hline & Fully adjusted $\ddagger+$ other antioxidants & $1 \cdot 13$ & $0.95,1.36$ & 1.26 & $0.90,1.76$ & $1 \cdot 15$ & $0.83,1.61$ & 1.08 & $0.78,1.48$ & 1.05 & $0.75,1.48$ \\
\hline Se & & & & $0<$ & $\leq 25 \mu \mathrm{g} / \mathrm{d}$ & $25<$ & $\leq 30 \mu \mathrm{g} / \mathrm{d}$ & $30<$ & $\leq 60 \mu \mathrm{g} / \mathrm{d}$ & & $\mu \mathrm{g} / \mathrm{d}$ \\
\hline & $n$ & & 46 & & 69 & & 17 & & 27 & & 33 \\
\hline & Unadjusted & 0.96 & $0.81,1 \cdot 13$ & $1 \cdot 10$ & $0.86,1.40$ & 0.99 & $0.61,1.61$ & 0.75 & $0.51,1.11$ & 0.85 & $0.60,1.20$ \\
\hline & Age- and sex-adjusted & 0.86 & $0.73,1.01$ & 0.99 & $0.78,1.25$ & 0.94 & $0.59,1.50$ & 0.64 & $0.44,0.93$ & 0.78 & $0.56,1 \cdot 10$ \\
\hline & Fully adjusted $\ddagger$ & 0.99 & $0.86,1 \cdot 15$ & $1 \cdot 13$ & $0.92,1.40$ & 0.95 & $0.63,1.45$ & 0.83 & $0.59,1 \cdot 16$ & 0.89 & $0.66,1.21$ \\
\hline & Fully adjusted $\ddagger+$ other antioxidants & 1.03 & $0.87,1.22$ & $1 \cdot 18$ & $0.94,1.47$ & 0.99 & $0.64,1.51$ & 0.86 & $0.61,1 \cdot 21$ & 0.92 & $0.67,1.26$ \\
\hline Zn§ & & & & & - & & - & & - & & - \\
\hline & $n$ & & 03 & & - & & - & & - & & - \\
\hline & Unadjusted & 0.96 & $0.83,1.11$ & & - & & - & & - & & - \\
\hline & Age- and sex-adjusted & 0.89 & $0.78,1.03$ & & - & & - & & - & & - \\
\hline & Fully adjusted $\ddagger$ & 1.04 & $0.91,1.18$ & & - & & - & & - & & - \\
\hline & Fully adjusted $\ddagger+$ other antioxidants & $1 \cdot 12$ & $0.96,1.30$ & & - & & - & & - & & - \\
\hline
\end{tabular}

* Reference group: no intake of nutrient of interest from supplements or medications.

†Binary coded as yes/no.

$\ddagger$ Adjusted for age (continuous), sex, education (low/high), BMI (continuous), BMI² (continuous), physical activity (active/inactive), smoking (current/former/never), alcohol consumption (none/moderate/high), cholesterol:HDL ratio

(continuous), actual hypertension (yes/no), CVD (yes/no), diabetes (yes/no), non-steroidal anti-inflammatory drug use (yes/no), and statin use (yes/no).
§ Division into quartiles was not possible due to distribution, because $40 \%$ of persons with regular intakes ingested $5 \mathrm{mg} \mathrm{Zn} / \mathrm{d}$. 


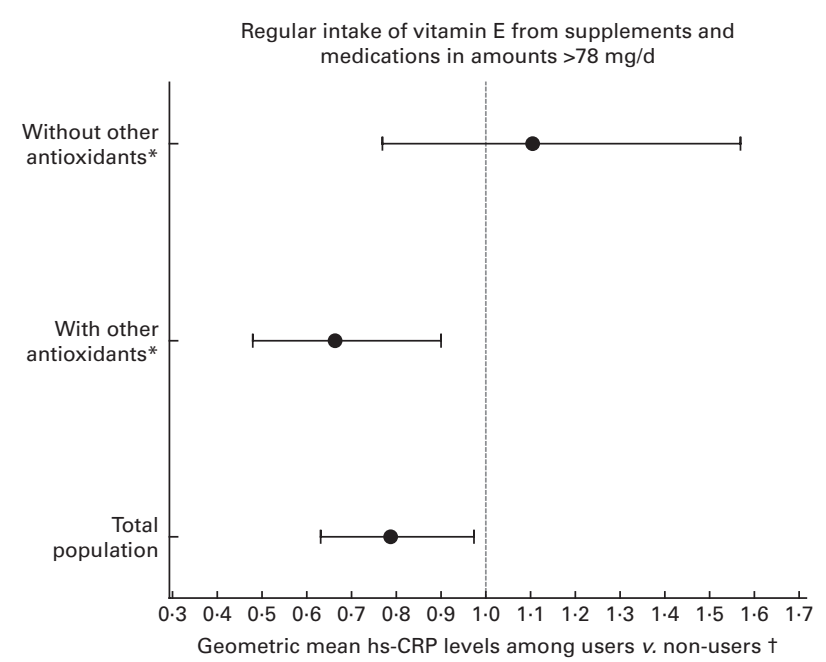

Fig. 1. Interaction between regularly ingested vitamin $E$ amounts in the upper quartile and intake of other antioxidants. Values are ratios of geometric mean hs-CRP, with their $95 \%$ confidence intervals represented by horizontal bars. * Intake of at least one of the other investigated antioxidants (vitamin C, carotenoids, selenium, and zinc). †Estimates result from fully adjusted linear regression models (adjusted for age (continuous), sex, education (low/high), BMI (continuous), $\mathrm{BMI}^{2}$ (continuous), physical activity (active/inactive), smoking (current/former/never), alcohol consumption (none/moderate/high), cholesterol:HDL ratio (continuous), actual hypertension (yes/no), CVD (yes/no), diabetes (yes/no), non-steroidal anti-inflammatory drug use (yes/no), and statin use (yes/no)). hs-CRP, high sensitivity C-reactive protein.

$P=0.45 ; \quad 0.76 \quad(95 \%$ CI $0.49,1.17), \quad P=0.21)$ (see online Supplementary Table S1). On the contrary, in persons who ingested vitamin E supplements only without any other antioxidants, higher $\alpha$-tocopherol levels tended to be associated with higher hs-CRP levels (ratios for quartiles three and four $v$. one, respectively: 1.62 (95\% CI $0.33,8.01$ ), $P=0.54 ; 1.47$ (95\% CI $0.34,6.39), P=0.59$ ) (see online Supplementary Table S1). Overall, associations were not significant possibly due to small numbers especially in the stratified analyses ( $n \leq 36$ in the group of subjects who did ingest other antioxidants besides vitamin $\mathrm{E}$, and $n \leq 11$ in the group of subjects who did not).

\section{Discussion}

Regular vitamin E intake in amounts above $78 \mathrm{mg} / \mathrm{d}$ was significantly associated with lower hs-CRP levels in the present study. Stratified analyses showed this association was found only in persons who used vitamin $\mathrm{E}$ in combination with other antioxidants. The interaction term for sex was not significant; however, associations were stronger in women and non-significant in men after stratification.

Vitamin $\mathrm{E}$ is a potent antioxidant that can reduce oxidative stress and influence inflammatory processes ${ }^{(35)}$. Direct antiinflammatory effects are triggered through several mechanisms including down regulation of the proinflammatory transcription factor $\mathrm{NF}-\mathrm{\kappa B}^{(36)}$, reduction of lipopolysaccharide-stimulated levels of the proinflammatory cytokine TNF- $\alpha^{(37)}$, and decrease of proinflammatory IL-1 $\beta$ by inhibition of 5-lipoxygenase, an enzyme involved in synthesis of inflammatory prostaglandins ${ }^{(38)}$. It is noteworthy that there is an interaction between inflammation and oxidative stress, implying that one condition triggers the other ${ }^{(39)}$. Oxidative stress is increased through the production of reactive oxygen and nitrogen species by immune cells. And these species do promote inflammation through the activation of NF- $\mathrm{BB}$ and the subsequent transcription of proinflammatory cytokines ${ }^{(39)}$. Therefore, an anti-inflammatory effect of vitamin $\mathrm{E}$ may be reasonable via both direct anti-inflammatory and also antioxidative pathways.

Supplementation of vitamin $\mathrm{E}$ alone might not be as favourable as compared to its combined supplementation with other antioxidants, because antioxidative action of vitamin $\mathrm{E}$ leads to the formation of oxidized vitamin $\mathrm{E}$, which has prooxidative potential if not regenerated. Vitamin $\mathrm{C}$ as a hydrophilic antioxidant is involved in the regeneration of oxidized vitamin $\mathrm{E}^{(40)}$. This could explain why vitamin $\mathrm{E}$ used particularly in combination with the other antioxidants, especially vitamin C, mostly supplemented in the present study, was most strongly associated with lower hs-CRP levels. Accordingly, Garcia-Bailo et al ${ }^{(39)}$ suggested that the combined administration of vitamin $\mathrm{C}$ and vitamin $\mathrm{E}$ might be more effective in reducing oxidative stress and inflammation than utilising either micronutrient on its own. Furthermore, it was proposed that there is a 'vitamin E regeneration system' based on the complex interaction of several antioxidants, which has to be considered when investigating vitamin E effectiveness ${ }^{(41)}$. Results from the present investigation support this hypothesis.

$\alpha$-Tocopherol is the only form of vitamin $\mathrm{E}$ used in supplements $^{(42)}$, and a moderate-to-strong correlation was observed in the present study between average daily intake amounts of vitamin $\mathrm{E}$ from supplements and $\alpha$-tocopherol levels in serum. Results from linear regression analyses for serum levels of $\alpha$-tocopherol as exposure were comparable to those found for intake amounts of vitamin $\mathrm{E}$ from supplements, i.e., higher $\alpha$-tocopherol levels tended to be associated with lower levels of hs-CRP in regular vitamin $\mathrm{E}$ supplement users, especially when they ingested other antioxidants as well. On the contrary, the association tended to be positive if other antioxidants were not ingested. Results regarding serum $\alpha$-tocopherol levels were, however, not significant, possibly because the number of subjects in each quartile was low since measurements were available only in a subsample of the study population. In previous studies both positive and negative associations between $\alpha$-tocopherol levels and CRP concentrations were found, whereas the concomitant use of (antioxidant) supplements was not considered in those studies ${ }^{(43,44)}$. Results from the present study suggest that the simultaneous use of other antioxidant supplements could be an effect modifier that needs to be taken into account.

In line with the present investigation, supplementation of vitamin E alone was not associated with reduced CRP levels in two intervention studies, where 800 and $400 \mathrm{IU}$ levels of vitamin $\mathrm{E} / \mathrm{d}$ were used respectively ${ }^{(45,46)}$, with the exception of another trial that used an extremely high amount of $1200 \mathrm{IU}$ vitamin $\mathrm{E} / \mathrm{d}^{(47)}$ (1 IU equating to $0.67 \mathrm{mg} R R R$ - $\alpha$-tocopherol). 
However, combined supplementation of $800 \mathrm{IU}$ vitamin E together with twenty-three other ingredients (among them vitamin $\mathrm{C}, \beta$-carotene, Se, and $\mathrm{Zn}$ ) reduced CRP levels in a randomized, double-blind, placebo-controlled trial ${ }^{(48)}$

As in the present analysis, other observational studies examining associations between nutrients and hs-CRP also reported for antioxidants stronger inverse associations among women as compared to those in $\operatorname{men}^{(3)}$, and similar associations for glucosamine and chondroitin ${ }^{(32)}$. Furthermore, in two intervention studies, no effect of vitamin $\mathrm{E}$ in combination with vitamin $\mathrm{C}$ and with vitamin $\mathrm{C}$ and $\beta$-carotene was observed in men with high cholesterol or with elevated homocysteine levels ${ }^{(49,50)}$. However, Floegel et $a l .{ }^{(4)}$ found in the US National Health and Nutrition Examination Survey no significant interaction on the basis of sex, and reported combined results for an inverse association of antioxidant intake from diet plus supplements with CRP concentrations. Further randomized controlled trials especially in women are warranted to investigate the association between supplementation of antioxidants and CRP levels.

Vitamin E intake amounts of $78 \mathrm{mg} / \mathrm{d}$ are well above the German reference values for daily vitamin $\mathrm{E}$ intake, which is set at $13 \mathrm{mg}$ for men and $14 \mathrm{mg}$ for women in the age group of 51 to 64 years $^{(51)}$. The actual European Tolerable Upper Intake Level for vitamin $\mathrm{E}$ was set at $300 \mathrm{mg} / \mathrm{d}$ in $2003^{(52)}$. During the subsequent years, meta-analyses of randomized trials reported an increased risk of mortality among users of high-dosage vitamin E supplements ${ }^{(53,54)}$. According to a review article published in the year 2005, several large or long-term clinical trials support the safety of vitamins $\mathrm{E}$ and $\mathrm{C}$ in combination ${ }^{(55)}$. However, the safety of antioxidative supplements is still debated ${ }^{(56)}$, and should further be investigated.

The major limitation of the present analysis is the crosssectional design; therefore, the observed association might not be causal. Furthermore, because of the inherent nature of observational studies, the said effect could be due to residual confounding, i.e., the subgroup of people with intake of several antioxidants could represent a healthier group particularly interested in health. However, analyses were adjusted for common lifestyle factors and use of other supplements. Moreover, a multitude of further important covariables was available for multivariable adjustment. Intake of dietary supplements over the previous $7 \mathrm{~d}$ may not truly reflect usual irregular intake behaviour. However, interview questions elicited details of participants' 'regular intake' and 'intake as needed', respectively, and only 'regular intake' of supplements was considered for analyses. The causal role of CRP levels and CVD progression is controversial $^{(57)}$. Nevertheless, CRP is still widely used as a clinical marker in contemporary studies ${ }^{(33,34,58,59)}$.

The major strength of the present study is the thorough assessment of supplements and medications used with detailed data on the composition of individual preparations, which allowed the conduct of dose-effect analyses. Moreover, serum levels of $\alpha$-tocopherol were additionally measured which supported the main findings. Also a hs-CRP assay was used to detect lower CRP levels which have the potential to predict CVD events ${ }^{(1)}$. Finally, the KORA F4 study represents a population-based survey; therefore, results are applicable to the general Southern German population.

\section{Conclusion}

Regular supplementation of vitamin E was associated with lower hs-CRP levels only in higher amounts and in combination with other antioxidants. Further intervention studies are needed to establish whether this association is causal. Furthermore, the safety of this kind of supplementation should be confirmed. If done so, the combined supplementation of vitamin $\mathrm{E}$ with other antioxidants could be a promising strategy for the prevention of inflammationrelated diseases in the general population.

\section{Supplementary material}

To view supplementary material for this article, please visit http://dx.doi.org/10.1017/S0007114515000902

\section{Acknowledgements}

We would like to thank the participants and the staff of the KORA F4 study for their efforts and contributions.

S. S., A. P., and B. T. designed the research; S. S., A. S., M. H., W. K., G. K., M. W., A. P., and B. T. conducted the research; S. S. and A. Z. performed the statistical analyses; S. S. wrote the paper and had primary responsibility for the final content; all authors read and approved the final manuscript.

The authors declare that they have no conflicts of interest.

The KORA research platform (KORA, Cooperative Research in the Region of Augsburg) was initiated and financed by the Helmholtz Zentrum München - German Research Center for Environmental Health, which is funded by the German Federal Ministry of Education and Research and by the State of Bavaria. Furthermore, KORA research was supported within the Munich Center of Health Sciences (MC Health), LudwigMaximilians-Universität, as part of an LMUinnovativ project. The funding agencies had no role in the design, analysis, findings, or the writing of this article.

\section{References}

1. Pearson TA (2003) Markers of inflammation and cardiovascular disease: application to clinical and public health practice: a statement for healthcare professionals from the Centers for Disease Control and Prevention and the American Heart Association. Circulation 107, 499-511.

2. Kolb H \& Mandrup-Poulsen T (2005) An immune origin of type 2 diabetes? Diabetologia 48, 1038-1050.

3. Scheurig AC, Thorand B, Fischer B, et al. (2008) Association between the intake of vitamins and trace elements from supplements and C-reactive protein: results of the MONICA/ KORA Augsburg study. Eur J Clin Nutr 62, 127-137.

4. Floegel A, Chung SJ, von Ruesten A, et al. (2011) Antioxidant intake from diet and supplements and elevated serum C-reactive protein and plasma homocysteine concentrations in US adults: a cross-sectional study. Public Health Nutr $\mathbf{1 4}$ 2055-2064. 
5. Bae SC, Jung WJ, Lee EJ, et al. (2009) Effects of antioxidant supplements intervention on the level of plasma inflammatory molecules and disease severity of rheumatoid arthritis patients. J Am Coll Nutr 28, 56-62.

6. Castillo R, Rodrigo R, Perez F, et al. (2011) Antioxidant therapy reduces oxidative and inflammatory tissue damage in patients subjected to cardiac surgery with extracorporeal circulation. Basic Clin Pharmacol Toxicol 108, 256-262.

7. Wood LG, Garg ML, Smart JM, et al. (2012) Manipulating antioxidant intake in asthma: a randomized controlled trial. Am J Clin Nutr 96, 534-543.

8. Daud ZA, Tubie B, Sheyman M, et al. (2013) Vitamin E tocotrienol supplementation improves lipid profiles in chronic hemodialysis patients. Vasc Health Risk Manag 9, 747-761.

9. Biniaz V, Sadeghi Shermeh M, Ebadi A, et al. (2014) Effect of vitamin C supplementation on C-reactive protein levels in patients undergoing hemodialysis: a randomized, double blind, placebo-controlled study. Nephrourol Mon 6, e13351.

10. Hercberg S, Galan P, Preziosi P, et al. (1998) Background and rationale behind the SU.VI.MAX Study, a prevention trial using nutritional doses of a combination of antioxidant vitamins and minerals to reduce cardiovascular diseases and cancers. SUpplementation en VItamines et Mineraux AntioXydants Study. Int J Vitam Nutr Res 68, 3-20.

11. Rathmann W, Strassburger K, Heier M, et al. (2009) Incidence of type 2 diabetes in the elderly German population and the effect of clinical and lifestyle risk factors: KORA S4/F4 cohort study. Diabet Med 26, 1212-1219.

12. Mühlberger N, Behrend C, Stark R, et al. (2003) [Databasesupported identification and entry of drug data in health studies - experience with the IDOM software]. Inform Biomet Epidemiol Med Biol 34, 601-611.

13. Schwab S, Heier M, Schneider A, et al. (2014) The use of dietary supplements among older persons in southern Germany - results from the KORA-age study. J Nutr Health Aging 18, 510-519.

14. Illig T, Gieger C, Zhai G, et al. (2010) A genome-wide perspective of genetic variation in human metabolism. Nat Genet 42, 137-141.

15. Dehaven CD, Evans AM, Dai H, et al. (2010) Organization of GC/MS and LC/MS metabolomics data into chemical libraries. J Cheminform 2, 9.

16. Boudonck K, Mitchell M, Wulff J, et al. (2009) Characterization of the biochemical variability of bovine milk using metabolomics. Metabolomics 5, 375-386.

17. World Health Organization (2000) Obesity: Preventing and Managing the Global Epidemic. Report of a WHO Consultation. World Health Organization Technical Report Series no. 894 , i-xii pp. $1-253$.

18. Meisinger C, Lowel H, Thorand B, et al. (2005) Leisure time physical activity and the risk of type 2 diabetes in men and women from the general population. The MONICA/KORA Augsburg Cohort Study. Diabetologia 48, 27-34.

19. Döring A, Filipiak B, Stieber J, et al. (1993) Trends in alcohol intake in a southern German population from 1984-1985 to 1989-1990: results of the MONICA Project Augsburg. J Stud Alcohol 54, 745-749.

20. World Health Organization, Rehm J, Room R, et al. (2004) Alcohol use. http://www.who.int/publications/cra/chapters/ volume1/0959-1108.pdf

21. American Heart Association (2014) What your cholesterol levels mean. http://www.heart.org/HEARTORG/Conditions/ Cholesterol/AboutCholesterol/What-Your-Cholesterol-LevelsMean_UCM_305562_Article.jsp

22. World Health Organization, International Society of Hypertension (1999) 1999 World Health Organization-International
Society of Hypertension Guidelines for the Management of Hypertension Guidelines Subcommittee. J Hypertens 17, $151-183$.

23. Morris MS, Sakakeeny L, Jacques PF, et al. (2010) Vitamin B-6 intake is inversely related to, and the requirement is affected by, inflammation status. J Nutr 140, 103-110.

24. Solini A, Santini E \& Ferrannini E (2006) Effect of short-term folic acid supplementation on insulin sensitivity and inflammatory markers in overweight subjects. Int J Obes (Lond) $\mathbf{3 0}$, 1197-1202.

25. Guerrero-Romero F, Bermudez-Pena C \& Rodriguez-Moran M (2011) Severe hypomagnesemia and low-grade inflammation in metabolic syndrome. Magnes Res 24, 45-53.

26. Nielsen FH, Johnson LK \& Zeng H (2010) Magnesium supplementation improves indicators of low magnesium status and inflammatory stress in adults older than 51 years with poor quality sleep. Magnes Res 23, 158-168.

27. Chacko SA, Song Y, Nathan L, et al. (2010) Relations of dietary magnesium intake to biomarkers of inflammation and endothelial dysfunction in an ethnically diverse cohort of postmenopausal women. Diabetes Care 33, 304-310.

28. Almoznino-Sarafian D, Berman S, Mor A, et al. (2007) Magnesium and C-reactive protein in heart failure: an anti-inflammatory effect of magnesium administration? Eur J Nutr 46, 230-237.

29. King DE, AG Mainous 3rd, Geesey ME, et al. (2005) Dietary magnesium and C-reactive protein levels. J Am Coll Nutr 24, 166-171.

30. Haynes BM, Pfeiffer CM, Sternberg MR, et al. (2013) Selected physiologic variables are weakly to moderately associated with 29 biomarkers of diet and nutrition, NHANES 20032006. J Nutr 143, 1001S-1010S.

31. Wang C, Li Y, Zhu K, et al. (2009) Effects of supplementation with multivitamin and mineral on blood pressure and C-reactive protein in obese Chinese women with increased cardiovascular disease risk. Asia Pac J Clin Nutr 18, $121-130$.

32. Kantor ED, Lampe JW, Vaughan TL, et al. (2012) Association between use of specialty dietary supplements and C-reactive protein concentrations. Am J Epidemiol 176, 1002-1013.

33. Simental-Mendia LE, Rodriguez-Moran $M$ \& GuerreroRomero F (2014) Oral magnesium supplementation decreases C-reactive protein levels in subjects with prediabetes and hypomagnesemia: a clinical randomized double-blind placebo-controlled trial. Arch Med Res 45, 325-330.

34. Chen N, Wan Z, Han SF, et al. (2014) Effect of vitamin D supplementation on the level of circulating high-sensitivity C-reactive protein: a meta-analysis of randomized controlled trials. Nutrients 6, 2206-2216.

35. Calder PC, Albers R, Antoine JM, et al. (2009) Inflammatory disease processes and interactions with nutrition. Br J Nutr 101, Suppl. 1, S1-S45.

36. Islam KN, Devaraj S \& Jialal I (1998) $\alpha$-Tocopherol enrichment of monocytes decreases agonist-induced adhesion to human endothelial cells. Circulation 98, 2255-2261.

37. Mol MJ, de Rijke YB, Demacker PN, et al. (1997) Plasma levels of lipid and cholesterol oxidation products and cytokines in diabetes mellitus and cigarette smoking: effects of vitamin E treatment. Atherosclerosis 129, 169-176.

38. Devaraj S \& Jialal I (1999) $\alpha$-Tocopherol decreases interleukin-1 $\beta$ release from activated human monocytes by inhibition of 5-lipoxygenase. Arterioscler Thromb Vasc Biol 19, 1125-1133.

39. Garcia-Bailo B, El-Sohemy A, Haddad PS, et al. (2011) Vitamins D, C, and $\mathrm{E}$ in the prevention of type 2 diabetes mellitus: modulation of inflammation and oxidative stress. Biologics 5, 7-19. 
40. Packer JE, Slater TF \& Willson RL (1979) Direct observation of a free radical interaction between vitamin $\mathrm{E}$ and vitamin $\mathrm{C}$. Nature 278, 737-738.

41. Nwose EU, Jelinek HF, Richards RS, et al. (2008) The 'vitamin E regeneration system' (VERS) and an algorithm to justify antioxidant supplementation in diabetes - a hypothesis. Med Hypotheses 70, 1002-1008.

42. Wolf $\mathrm{G}$ (2006) How an increased intake of $\alpha$-tocopherol can suppress the bioavailability of $\gamma$-tocopherol. Nutr Rev 64, 295-299.

43. van Herpen-Broekmans WM, Klopping-Ketelaars IA, Bots ML, et al. (2004) Serum carotenoids and vitamins in relation to markers of endothelial function and inflammation. Eur $J$ Epidemiol 19, 915-921.

44. Cooney RV, Franke AA, Wilkens LR, et al. (2008) Elevated plasma $\gamma$-tocopherol and decreased $\alpha$-tocopherol in men are associated with inflammatory markers and decreased plasma 25-OH vitamin D. Nutr Cancer 60, Suppl. 1, 21-29.

45. Block G, Jensen CD, Dalvi TB, et al. (2009) Vitamin C treatment reduces elevated C-reactive protein. Free Radic Biol Med 46, 70-77.

46. Kaul N, Devaraj S, Grundy SM, et al. (2001) Failure to demonstrate a major anti-inflammatory effect with $\alpha$-tocopherol supplementation ( $400 \mathrm{IU} /$ day) in normal subjects. Am J Cardiol 87, 1320-1323.

47. Devaraj S \& Jialal I (2000) $\alpha$-Tocopherol supplementation decreases serum C-reactive protein and monocyte interleukin-6 levels in normal volunteers and type 2 diabetic patients. Free Radic Biol Med 29, 790-792.

48. Church TS, Earnest CP, Wood KA, et al. (2003) Reduction of $\mathrm{C}$-reactive protein levels through use of a multivitamin. Am J Med 115, 702-707.

49. Bruunsgaard H, Poulsen HE, Pedersen BK, et al. (2003) Long-term combined supplementations with $\alpha$-tocopherol and vitamin $C$ have no detectable anti-inflammatory effects in healthy men. J Nutr 133, 1170-1173.

50. O'Doherty MG, Gilchrist SE, Young IS, et al. (2010) Effect of supplementation with B vitamins and antioxidants on levels of asymmetric dimethylarginine (ADMA) and C-reactive protein (CRP): a double-blind, randomised, factorial design, placebo-controlled trial. Eur J Nutr 49, 483-492.

51. German Nutrition Society, Austrian Nutrition Society, Swiss Nutrition Society, et al. (2000) [The Reference Values for Nutrient Intake], 1st ed. Frankfurt am Main: Umschau Braus.

52. European Food Safety Authority (2006) Tolerable Upper Intake Levels for Vitamins and Minerals. Scientific Committee on Food, Scientific Panel on Dietetic Products, Nutrition and Allergies. http://www.efsa.europa.eu/en/ndatopics/docs/ ndatolerableuil.pdf (accessed 28 July 2014).

53. Miller ER 3rd, Pastor-Barriuso R, Dalal D, et al. (2005) Meta-analysis: high-dosage vitamin E supplementation may increase all-cause mortality. Ann Intern Med 142, 37-46.

54. Bjelakovic G, Nikolova D \& Gluud C (2013) Meta-regression analyses, meta-analyses, and trial sequential analyses of the effects of supplementation with $\beta$-carotene, vitamin $\mathrm{A}$, and vitamin $\mathrm{E}$ singly or in different combinations on all-cause mortality: do we have evidence for lack of harm? PLOS ONE 8, e74558.

55. Hathcock JN, Azzi A, Blumberg J, et al. (2005) Vitamins E and $\mathrm{C}$ are safe across a broad range of intakes. Am J Clin Nutr 81, 736-745.

56. Bjelakovic G, Nikolova D \& Gluud C (2014) Antioxidant supplements and mortality. Curr Opin Clin Nutr Metab Care 17, $40-44$.

57. Zacho J, Tybjaerg-Hansen A, Jensen JS, et al. (2008) Genetically elevated C-reactive protein and ischemic vascular disease. $N$ Engl J Med 359, 1897-1908.

58. Wang MX, Jiao JH, Li ZY, et al. (2013) Lutein supplementation reduces plasma lipid peroxidation and C-reactive protein in healthy nonsmokers. Atherosclerosis 227, 380-385.

59. Ong KL, Allison MA, Cheung BM, et al. (2013) Trends in C-reactive protein levels in US adults from 1999 to 2010. Am J Epidemiol 177, 1430-1442. 